\title{
A Dynamic Programming Based Demand Response Management of High Rise Residential Buildings using DERs and Electric Vehicles
}

\author{
Bharat Singh Bhambhu \\ Delta Electronics India PVT. LTD. Gurufram Haryana, 12001 India
}

Received 22 February 2021; Accepted 2 March 2021

\begin{abstract}
The vast majority of the potential electricity consumers in urban areas, are high rise residential buildings. The power requirements of these buildings, form a major portion of the power demand on the Smart Grid (SG). So, the energy management of such residential buildings would play a crucial role in reducing the burden off the grid. However, in these high rise buildings, large area is available on the rooftop and in the basement. The roof top area can be utilized for the installation of PV and wind system. Whereas, the basement area can be used for setting up of Charging Station (CS). The purpose of the CS is to facilitate the charging and discharging of the Electric Vehicles (EV's). The batteries of the EVs' parked in the CS can be utilized for storing and delivering of electrical energy which will help in Demand Response Management (DRM). Moreover, the PV panels, wind system and EVs batteries all are in grid connected mode. Hence, this paper proposes a novel scheme, which controls the charging and discharging of the EVs' batteries for DRM using Dynamic Programming. The results show that controlled charging and discharging of the EVs' batteries helped in DRM of the high rise building and power dependency on the SG has been reduced.
\end{abstract}

Keywords: Charging Station, Demand Response Management, Distributed energy resources, Electric Vehicles, Smart Grid, high rise buildings.

\section{Introduction}

The methods for transporting electricity dates back to the earlier centuries. Since then, the technologies used for transporting and generating electricity have been modified drastically. This has resulted in the evolution of the entire grid system. The grid has been evolved in a manner that the demand and supply gap can be reduced to the minimal extent with less human interference. Thus, the gradual transformation over the years has given a new shape to the existing grid system. Hence, the concept of Smart Grid (SG) has been unfolded timely [1].

$\mathrm{SG}$ is the integration of modern technologies and intelligence techniques into the existing grid [2]. In the SG three main type of electrical loads are present i.e., industrial, residential, and agricultural, but among them residential loads form a major portion of the total demand on SG. Since, most of the residential loads are in urban areas and in these areas, high rise residential buildings are mostly seen, so the energy management of such buildings would be crucial.

Residential Buildings are the bigger aspect of the smart homes consisting of several apartments. A large area is available at the roof top and in the basement of high rise buildings. Moreover, conventionally the basement area is used for parking of the vehicles. However, in future, Electric Vehicles (EVs') will be mostly seen and therefore the area below the building can be used for setting up of Charging Station (CS). The purpose of the CS is to facilitate the charging and discharging of the EVs. The CS will control the EVs' batteries charging and discharging, which will help in Demand Response Management (DRM). Furthermore, the roof top area

*E-mail address: Bs12bhambhu@gmail.com ISSN: 1791-2377 @ 2021 School of Science, IHU. All rights reserved. doi:10.25103/jestr.142.25 can be utilized for the installation of PV panels and wind system, which are used as Distributed Energy Resources (DERs'). These DERs' are used to manage the demand response of the building and to make self-sufficient energy building.

DERs' are the power sources that are non-uniformly distributed within a region in order to meet the power demand [3], [4]. Till now, the role of DERs' for DRM in the high rise residential buildings has not been explored to the best of authors' knowledge [5], [6]. In this work, the roof top area of the building has been utilized for the installation of the DERs' so that the energy needs of the building can be met. Apart from this, the batteries of the EVs' can also be explored for the purpose of DRM. Moreover, if the power generated by the DERs is more than the load, the excess power is stored in the EVs batteries. In case, the generation is less, then the energy stored in the EVs' batteries is utilized. However, if the demand is still left unfulfilled then the charging and discharging rates of the EVs are altered. Moreover, many works has been done in Home Energy Management System (HEMS), but the role of EVs' has not been considered. For instant, Chang et al. in [7] proposed a novel HEMS using stochastic optimization technique. In this a communication network is set up between a number of HEMS such that the balance of power is maintained. Although, the DRM is achieved but the authors failed to incorporate DERs' and EVs'. Nevertheless, DRM of a single smart home using DERs' has been done, but this has not been extended to residential buildings consisting of a number of apartments. If the DRM of high rise residential buildings is carried out, a major portion of the load on the SG can be removed. In order to make the above discussion even more beneficial, detailed literature study has been carried out. Wang et. al [8], proposed a genetic algorithm based demand response control, for minimizing the peak demand caused due 
to the group of high rise buildings. The above work overcame the limitations caused due to the conventional methods for demand response. Similarly, authors in [9], extended the concept of demand response to the case of commercial high rise buildings, by doing priority-based load shedding. But in both the above works, authors failed to incorporate the same concept for the residential high rise buildings. Moreover, the authors didn't considered the roles of DERs' and the alteration in the charging and discharging rates of EVs' batteries for DRM. In fact, work has been done for managing the demand response of the buildings, but it was just limited to controlling the heating and cooling parameters while reducing the electricity cost. For instance, Yoon et. al in [10], developed a demand response controller for reducing the power consumption due to heating, ventilating, and air conditioning (HVAC) loads. Similarly, authors in [11], proposed that the flexible use of HVAC systems can balance the power generation from DERs' in buildings. Moreover, authors in [12], proposed active demand response control strategy for optimizing the energy consumption as well as the comfort level of the building. In order to do so, distributed energy systems and storage elements along with the model predictive control were integrated within the building. Although, in all the three works authors reduced the energy consumption and maintained the comfort level of the residential building, but were incompetent in utilizing the storage system of the EVs for DRM. In [13], the authors developed DRM scheme for a grid-connected photovoltaic battery hybrid system subjected to constraints, such as-power balance, solar output and battery capacity. However, they failed to consider the State of Charge (SOC) variations of the batteries used, in order to optimized the system. Furthermore, Mesari c et. al in [14], focused on reducing the intermittency issues of renewable energy resources by incorporating EVs' as dispatchable energy sources. Although, the power from conventional generation was reduced, but the dynamic behaviour of the EVs' batteries was left unexplored for DRM. Authors in [15], proposed an energy management system for facilitating power exchange among micro grids. In this, they utilized multiagent based approach where all the DERs' acts as agents. Similarly in [16], authors proposed a multi-agent system for controlling the active demand using the plug-in EVs'. To make the work effective, individual agents were proposed which shifted the total demand to the off peak hours. Unfortunately, for efficient working of above scheme need arises for setting up of a strong communication network among the agents for effectual DRM. Ghasemi et. al in [17], observed that the utilization of battery storage system of EVs reduces the penalty cost introduced due to the intermittent nature of wind power. Although the author modified the charging rates of the EVs' batteries based on hourly electricity prices but were incompetent in controlling the charging and discharging rates as per the variations in power demand. Brusco et. al [18] formulated a DRM scheme using a central control entity for an Italian housing area. Although, the project was initiated for a large housing area where a large number of EVs' can be present. But, the authors failed to include EVs' batteries contributions for the management of demand response.

Researchers in [19], designed a framework for DRM based on iterative distributed algorithm for decreasing the complexity caused due DERs'. The authors implemented the above scheme at commercial site equipped with on-site PV panels, EV charge stations and a battery electric storage unit. Nyan et. al [20] implemented the concept of quadratic and dynamic programming for the coordinated charging of the EVs', thus minimizing the power losses and main grid factor.
However, the authors were negligent for utilizing the EVs' batteries in both charging and discharging modes. Ozturk et al. in [21], managed the demand response of a smart home by forecasting the optimal run time of each residential loads. The authors here designed a decision support system for reengineering the electrical load. On the same line, Tischer et. al in [22], put forward the concept of a dynamic programming approach for energy management purpose of smart home. However, in both the above work, the researchers are unable to implement the concept on the high rise residential buildings. Hence, the aforementioned discussion has motivated the authors to manage the demand response of the high rise residential buildings by the utilization of DERs' installed at the roof top and the EVs' parked at the CS.

\subsection{Motivation}

The high rise residential buildings in the urbanized areas create large demand supply gap. Moreover, less work has been done for the energy management of these buildings. Although, work has been done, but it was confined to commercial buildings only [8], [9]. Thus through this work, we intend to manage the energy requirement of such high rise residential buildings which are intelligent and autonomous. The energy requirements of these buildings are managed by the installation of DERs at the roof top of the building. Besides this, a CS has also been formulated which utilizes the storage system of the EVs for meeting the energy requirements. Besides, researchers in [15], [16], used multi-agent based system for DRM, which needs strong communication network. But, this drawback has been overcome in this scheme, where there is less requirement for setting up such a network. The proposed scheme is also more practical as the same EV has been considered in both charging and discharging mode for DRM. Furthermore, conventionally the concept of dynamic programing has been used for minimizing the electricity tariff as in literature [22]. In this paper, the same technique has been extended for controlling the charging and discharging rate of the EVs' batteries.

\subsection{Contribution}

Hence, the major contributions of this paper are summarized as follows.

- A system framework has been designed for managing the demand response of the high rise residential building in order to reduce the dependency on the SG.

- In this novel scheme, a CS has been proposed. EVs' available at the CS has been utilized in both charging and discharging modes. The energy stored in the EVs' batteries is utilized for managing the demand response.

- Mathematical formulation has been done for DRM for optimally utilizing EVs' batteries and DERs'.

- Algorithm based on the concept of Dynamic Programming has been proposed, for controlling the charging and discharging rates of the EVs' batteries.

\section{Proposed system}

In this section, the proposed system has been elaborated with the help of the schematic diagram as shown in Fig. 1.

The high rise residential building is installed with the DERs' such as-PV panels and wind turbine for meeting the demand of the residential building. Moreover, a suitable converter has been used for converting the DC power to the AC. Along with this, a CS is also set up in the basement of the building as a storage device, for the utilization of the EVs' 
batteries. Moreover, the energy stored in the EVs batteries supports the power generated from the DERs. Furthermore, the residential building has been connected to the SG through a switch, so that the excess power needs of the building can be fulfilled as well as the additional power of the DERs' can be diverted to the SG.

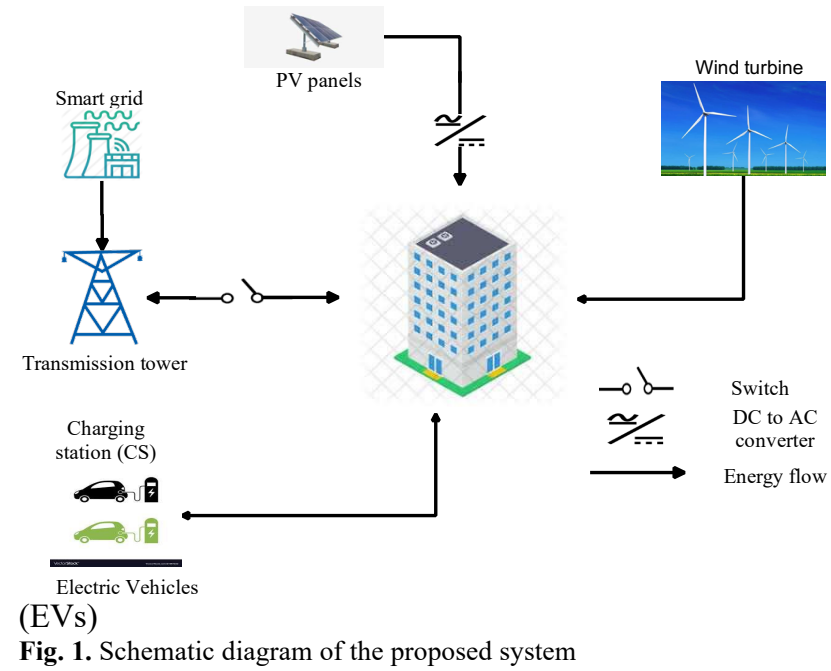

\subsection{Working Methodology}

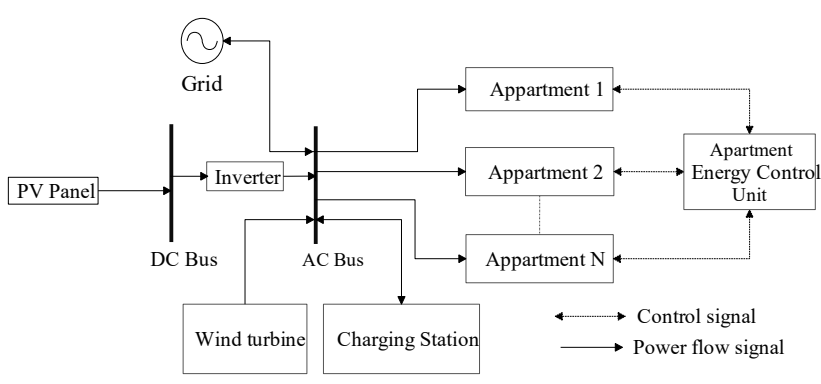

Fig. 2. Block diagram of the proposed system

Through this Section, the working of the proposed system has been shown in Fig. 2, which depicts the power flow within the high rise residential building. As can be seen from the figure, Apartment Energy Control Unit receives the information regarding power generated by the DERs' and the power demand of the apartments. Depending upon this information, this unit gives signal to the Charging Station Energy Control Unit, present at CS. This unit as depicted in Fig 3, controls the $C_{\text {rate }}$ and $D_{\text {rate }}$ of EVs' batteries such that the demand response can be met if the power available from the DERs' is not sufficient. Moreover, if the demand still remains unfulfilled or the energy of the EVs, batteries is exhausted, then the power is borrowed from the SG. Besides, if the power generated by the DERs' is in excess then the additional power is stored in the EVs' batteries. In case, the SOC levels of all the EVs' are fulfilled, then the remaining power is diverted to the SG. Accordingly, EVs' batteries can either charge or discharge, thus allowing bidirectional flow of power at the CS.

Fig. 3 shows the detailed schematic diagram of the CS, comprising of an inverter, DC-DC converter, battery and the Charging Station Energy Control Unit. This control unit controls the $\mathrm{C}_{\text {rate }}$ and $\mathrm{D}_{\text {rate }}$ of the EVs' batteries for managing the demand response of the high rise residential building.

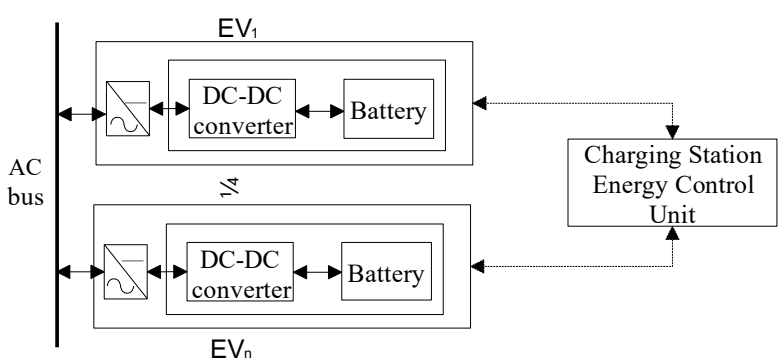

Fig. 3. Charging station

\section{Mathematical formulation}

Demand response if not managed can pose significant problems such as-voltage and frequency fluctuations, instability of the main grid. Therefore, need arises to manage the demand of the high rise buildings. Hence, in this section, the mathematical formulation of the components utilized for managing the demand response has been presented in detail.

PV panel: Roof top PV panels have been utilized for managing the partial load demand of the high rise residential buildings. Depending upon the intensity of solar radiation, efficiency and surface area of the PV panel, the power generated by the panel is given below.

$\mathrm{P}_{\mathrm{pv}}=\mathrm{I}_{\mathrm{f}} \mathrm{n}_{\mathrm{pv}} \mathrm{S}_{\mathrm{a}}$

where, $I_{\mathrm{f}}$ is the incident ray factor, $\mathrm{n}_{\mathrm{pv}}$ is the efficiency and $\mathrm{S}_{\mathrm{a}}$ is the surface area of the panel. Therefore, the energy generated by the PV panel in $\Delta \mathrm{t}$ time.

$\mathrm{E}_{\mathrm{pv}}=\mathrm{P}_{\mathrm{pv}} \Delta \mathrm{t}$

Wind Turbine System: In order to manage the demand response of the high rise residential building, wind turbine system has also been installed along with the PV panels. The power generated by these wind turbine system $\left(\mathrm{P}_{\mathrm{w}}\right)$, depends upon the cube of the velocity of wind $\left(\mathrm{V}_{\mathrm{w}}\right)$, power coefficient $\left(C_{p}\right)$, density of air $(\lambda)$, and the surface area of the blades $\left(S_{w}\right)$. The power coefficient $\mathrm{Cp}$ has a maximum value of 0.593 .

$\mathrm{P}_{\mathrm{w}}=1 / 2 \lambda \mathrm{C}_{\mathrm{p}} \mathrm{S}_{\mathrm{w}} \mathrm{v}_{\mathrm{w}}^{3}$

Where,

$\mathrm{C}_{\mathrm{p}}=\mathrm{P}_{\mathrm{w}} / \mathrm{P}$

In the above equation, $\mathrm{P}$ denotes the total wind power flowing into the wind blades at a given velocity.

Apartment Energy Control Unit: This control unit, receives the information regarding power generated by the DERs' and the power demand of the apartments. The total power demand of the high rise residential building can be estimated using below mentioned equation.

$P_{d}^{\text {total }}=\sum_{k=1}^{n} P_{d}^{k}$

where, $P_{d}^{k}$ is the power requirement of one of the apartment in the high rise residential building at any instant $t$. This power availability information of all the apartments are sent to the control unit through a home area network which may use wired or wireless technologies such as Wi-Fi and ZigBee. The total power demand of the apartments, is catered by utilizing 
the power generated by DERs' installed at the rooftop of the residential building. Sometimes, the power from DERs' may not be able to match the apartments demand response, which then has to be managed by the utilization of EVs' batteries. Henceforth, three conditions may arise due to the mismatch of power between the DERs and the total demand, which has been discussed and elaborated below.

- Case 1: If $P_{P V}+P_{w}>P_{d}^{\text {total }}$ i.e., the power available from the DERs' is more than the load demand of the residential building. In this case, the excess power from the DERs' is utilized for full fulling the SOC levels of the EVs parked at CS, such that the power transfered to the grid is optimal for all slots. the excess power from the DERs' is utilized for the charging of EVs' batteries, at altered $C_{\text {rate }}$. However, if the SOC level of all the EVs' batteries is fulfilled in the time slot $\Delta t$ and the power from the DERs' is still in excess, then this additional power is dispatch to the SG.

- Case 2: If $P_{P V}+P_{w}<P_{d}^{\text {total }}$ i.e., the generated power is not able to cater the total load. In this case, the additional power is met by utilizing the EVs batteries available at CS. - Case 3: If $P_{P V}+P_{w}+P_{E V}^{\text {net }}<P_{d}^{\text {total }}$ i.e, the power available from the DERs' and the power from EVs' batteries is insufficient. Then, the additional power $\left(P_{d}^{\text {total }}-\left(P_{P V}+P_{w}+P_{E V}^{n e t}\right)\right)$ is borrowed from the SG for that slot.

Charging Station: The basement area of the high rise residential building has been utilized for setting up of the CS, where EVs' are parked. EVs' batteries have been utilized for DRM by controlling their $\mathrm{C}_{\text {rate }}$ and $\mathrm{D}_{\text {rate }}$ respectively. Suppose, there are $\mathrm{N}$ number of EVs' batteries available in the grid connected mode, out of which $\mathrm{N}_{\mathrm{c}}$ and $\mathrm{N}_{\mathrm{d}}$, are charging and discharging respectively at any instant $t$. Therefore,

$N_{c}+N_{d}=N$

Since, it has been assumed, that the same EV battery can be used in different mode of operations i.e charging and discharging in different time slots. Thus, at any instant $t$, the energy generated by the EV battery when it is discharging, let be $\left(E_{n, G}\right)$ and energy consumed by the same EV while it is charging be $\left(\mathrm{E}_{\mathrm{m}, \mathrm{C}}\right) \mathrm{kWh}$ respectively. Then,

$E_{n, G}=\left(S O C_{t-\Delta t}^{E V}-S O C_{t}^{E V}\right) E_{\text {rated }}^{E V}$

$E_{m, C}=\left(S O C_{t}^{E V}-S O C_{t-\Delta t}^{E V}\right) E_{\text {rated }}^{E V}$

where, $\mathrm{E}_{\text {rated }}{ }^{\mathrm{EV}}$ represents the rated battery capacity of the $\mathrm{EV}$ battery, $\mathrm{SOC}_{\mathrm{t}}^{\mathrm{EV}}$ and $\mathrm{SOC}_{\mathrm{t}}^{\mathrm{EV}}{ }_{-\Delta \mathrm{t}}$ represents the SOC level at instant $(t)$ and $(t-\Delta t)$ respectively. Thus, the total energy consumed $\left(\mathrm{E}_{\mathrm{V}, \mathrm{C}}(\mathrm{t})\right)$ and delivered $\left(\mathrm{E}_{\mathrm{V}, \mathrm{G}}(\mathrm{t})\right)$ by the EVs' batteries at any instant $t$ can be computed using below mentioned equations.

$E_{E V, G}(t)=\sum_{n=1}^{d} E_{n, G}$
$E_{E V, C}(t)=\sum_{m=1}^{c} E_{m, C}$

Therefore, the net energy and power available at the ac bus is given by:

$$
\begin{aligned}
& E_{E V}^{n e t}(t)=E_{E V, G}(t)-E_{E V, C}(t) \\
& P_{E V}^{n e t}(t)=E_{E V}^{n e t}(t) / \Delta t
\end{aligned}
$$

where, $P_{E V \text {,net }}(t)$ is the net power available from the EVs' batteries at any instant $t$.

In order to control the $\mathrm{P}_{\mathrm{EV} \text {,net }}(\mathrm{t})$ between the $\mathrm{CS}$ and the $\mathrm{AC}$ bus, a Charging Station Energy Control Unit has been proposed. This unit receives the power requirement information from the Apartment Energy Control Unit. On the basis of this information, it alters the $\mathrm{C}_{\text {rate }}$ and $\mathrm{D}_{\text {rate }}$ of the EVs' batteries so that the power required at the $\mathrm{AC}$ bus can be met. Moreover, it prevents the overcharging and the over discharging of the EVs' batteries by checking the SOC level at each instant. The $C_{\text {rate }}$ and $D_{\text {rate }}$ of the EVs batteries is also limited by this controller such that the power fetched or diverted to the batteries doesn't occurs beyond the limits mentioned below.

$$
\begin{aligned}
& C_{\text {rate }}^{\min } \leq C_{\text {rate }} \leq C_{\text {rate }}^{\max } \\
& D_{\text {rate }}^{\min } \leq D_{\text {rate }} \leq D_{\text {rate }}^{\max } \\
& S O C_{\text {min }}^{E V} \leq S O C_{t}^{E V} \leq S O C_{\text {max }}^{E V}
\end{aligned}
$$

where, $C_{\text {rate }}^{\min }$ and $C_{\text {rate }}^{\text {max }}$ represents the minimum and maximum $\mathrm{C}_{\text {rate }}$ of the EVs' batteries. Whereas, $S O C_{\max }^{E V}$ and $S O C_{\min }^{E V}$ represents the minimum and maximum SOC levels.

\section{Dynamic programming based charge control}

\subsection{Of evs' batteries}

This Section presents the detailed methodology of the Charging Station Energy Control Unit and the algorithms based on the Dynamic Programming.

A. Methodology

The flow chart depicting the complete scheme has been shown in Fig. 4. For analyzing the system on real-time, the entire duration of 24 hrs has been divided into 96 slots each of 15 minutes. The power generated by the PV panel $\left(\mathrm{P}_{\mathrm{PV}}\right)$, power available from the wind turbine $\left(\mathrm{P}_{\mathrm{w}}\right)$ and the total load demand $\left(P_{d}^{\text {total }}\right)$ are computed using equations (1), (3), and (8), respectively. The values of $\mathrm{P}_{\mathrm{PV}}$ and $\mathrm{P}_{\mathrm{w}}$ are variable, which depend upon the factors as discussed in section (III)

For the given time slot, the power left unfulfilled $\left(\mathrm{P}_{\text {grid }}\right)$ of the high rise residential building is calculated, which is formulated by equation as mentioned below.

$P_{\text {grid }}=P_{d}^{\text {total }}-\left(P_{w}+P_{P V}+P_{E V}^{n e t}\right)$

where, $P_{E V}^{n e t}$ is the net power of the EVs batteries.

The objective of this paper is to manage the demand of the high rise residential building by the utilization of DERs and the EVs batteries. First, the demand response is managed by the DERs installed at the roof top of the building. If the power from DERs is insufficient, then it is managed by using the stored energy in the EVs batteries parked at the CS. If it is still left unmet, then $\mathrm{C}_{\text {rate }}$ and $\mathrm{D}_{\text {rate }}$ of the batteries are altered. Therefore, a new parameter $\Delta \mathrm{P}_{\text {grid }}$ has been formulated which takes only the power from DERs into account for the purpose of DRM, as mentioned by the below equation.

$\Delta P_{\text {grid }}=P_{d}^{\text {total }}-\left(P_{w}+P_{P V}\right)$

This $\Delta \mathrm{P}_{\text {grid }}$ is the excess demand that has to be met by utilizing the EVs' batteries. Moreover, there are $\mathrm{N}_{\mathrm{d}}$ and $\mathrm{N}_{\mathrm{c}}$ number of discharging and charging EVs' batteries available 
at the CS, which will help in supporting the excess demand of the high rise building i.e., $\Delta \mathrm{P}_{\text {grid. }}$.

The net power available from the EVs' batteries $\mathrm{P}_{\mathrm{EV}}{ }^{\text {net }}$ at the $\mathrm{AC}$ bus can be computed according to the below mentioned equation.

$$
\begin{aligned}
& P_{E V}^{n e t}=N_{d} P_{\text {rated }} D_{\text {rate }}-N_{c} P_{\text {rated }} C_{\text {rate }} \\
& N_{d} P_{\text {rated }} D_{\text {rate }}-N_{c} P_{\text {rated }} C_{\text {rate }}=\Delta P_{\text {grid }} \\
& N_{d} D_{\text {rate }}-N_{c} C_{\text {rate }}=\Delta P_{\text {grid }} /\left(P_{\text {rated }}\right)
\end{aligned}
$$

Moreover, the $\mathrm{D}_{\text {rate }}$ and $\mathrm{C}_{\text {rate }}$ of the EVs' batteries that are in the discharging and charging mode is given by equation given below.

$$
\begin{aligned}
& D_{\text {rate }}=\left(\Delta P_{\text {grid }} /\left(P_{\text {rated }} N_{d}\right)\right)+\left(N_{c} / N_{d}\right) C_{\text {rate }} \\
& C_{\text {rate }}=\left(N_{d} / N_{c}\right) D_{\text {rate }}-\left(\Delta P_{\text {grid }} /\left(P_{\text {rated }} N_{c}\right)\right)
\end{aligned}
$$

where, $\mathrm{P}_{\text {rated }}$ is the rated power corresponding to $\mathrm{E}_{\text {rated }}$ that can be extracted or feed into the EV battery in time slot $\Delta t$ at $D_{\text {rate }}$ or $\mathrm{C}_{\text {rate }}$ of 1 . In order to make the whole scheme worthful for optimized DRM while controlling the SOC levels of EVs batteries, following cases may arise:

- $\quad$ Case 1: If $\Delta \mathrm{P}_{\text {grid }}>0$ i.e., the DERs are unable to meet the total demand of the high rise residential building. Hence, the excess power is borrowed from the energy stored in the EVs batteries available at charging station.

Case 2: If $\Delta \mathrm{P}_{\text {grid }}>0$ and all the EVs' that are present in the high rise residential building are in charging mode. In such a scenario, the DP Algorithm won't allow the EVs' batteries to participate in DRM for that time slot. Hence, the $\mathrm{C}_{\text {rate }}$ of the EVs' batteries is reduced to zero i.e., all the EVs' are isolated from the SG. The excess power required for the DRM is borrowed from the SG.

- $\quad$ Case 3: If $\Delta \mathrm{P}_{\text {grid }}<0$ i.e., the power generated by the DERs is more then sufficient to manage the demand response of the high rise residential building. In this case, the additional power from the DERs is utilized for charging the EVs batteries so the power feed back to the grid is optimum.

- Case 4: If $\Delta \mathrm{P}_{\text {grid }}<0$ and all the EVs' batteries that are present in the high rise residential building are in discharging mode. Hence, the DP Algorithm will reduce the $\mathrm{D}_{\text {rate }}$ of the EVs' batteries to zero i.e., all the EVs' are isolated from the SG. The additional power from the DERs after managing the demand response is diverted to the SG. DRM using Dynamic Programming has been illustrated through algorithm (1).

\subsection{Dynamic Programming Approach}

A Dynamic Programming algorithm is the optimization technique that examines the previous sub problems and combine their solutions to give the best solution for the given problem. Traditionally, the concept of Dynamic Programming has been used for cost optimization problem, but here, the same concept has been extended for the minimization of power. The system that has been modelled here, consists of DERs' as the generating units and the EVs' batteries as the storing devices. For minimizing the power within the system, the $C_{\text {rate }}$ and $D_{\text {rate }}$ of the charging and discharging EVs' has been controlled using Dynamic Programming. In order to do so, two parameters are required for optimizing the performance function, one is the state variable and other is the control variable. The state variable is the one whose future value depends on the previous one and control variable, controls the value of the state variable. From here, it can be concluded that SOCs of the EVs' batteries are the state variables and $\mathrm{C}_{\text {rate, }}$, and $\mathrm{D}_{\text {rate }}$ are the control variable.

But since the SOC, $\mathrm{C}_{\text {rate }}$, and $\mathrm{D}_{\text {rate }}$ are the continuous variables, and before solving the eq. (37) and (38) in forward, it is essential to convert the variables in discrete values as shown in Fig. 5 and Fig. 6 respectively. The accuracy of the given objective depends on the numbers of grid points. Grid points are defined as point of the intersection of stage and step lines which contain the values of the state variables. So, higher resolution of discretization of the state space and time would increase the number of grid points.

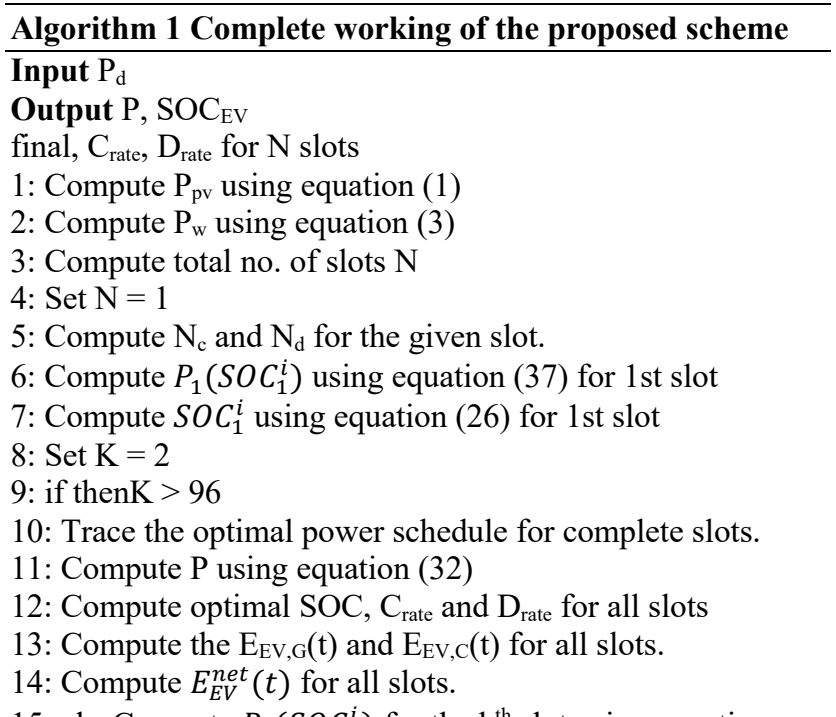
15: elseCompute $P_{k}\left(S O C_{k}^{i}\right)$ for the $\mathrm{k}^{\text {th }}$ slot using equation (38) based on Dynamic Programming.

16: Compute for all steps in period $\mathrm{k}$

17: compute Pgrid using equation (33) for each step of the $\mathrm{k}^{\text {th }}$ slot.

18: Save in the Lowest Power Strategies.

19: Set $K=N+1$

20: end if

This would increase the optimality of the given objective function. But, will increase the computation load required to calculate the global optimum. The continuous state SOC is discretized into finite points, and the number of discretized state, $\mathrm{S}$ is given by eq. (23):

$S=\left(S O C_{\max }-S O C_{\min }\right) / \triangle S O C$

where, $\triangle \mathrm{SOC}$ is the increment of the discretized SOC.

Similarly, the discretized value of $\mathrm{C}_{\text {rate }}$ and $\mathrm{D}_{\text {rate }}$ is given by eq. (24) and eq. (25) respectively.

$C=\left(C_{\text {rate }}^{\max }-C_{\text {rate }}^{\min }\right) / \Delta C$

$D=\left(D_{\text {rate }}^{\max }-D_{\text {rate }}^{\min }\right) / \Delta D$

where, $\Delta \mathrm{C}$ is the increment of the discretized $\mathrm{C}_{\text {rate }}$ and $\Delta \mathrm{D}$ is the increment of the discretized $D_{\text {rate }}$. 


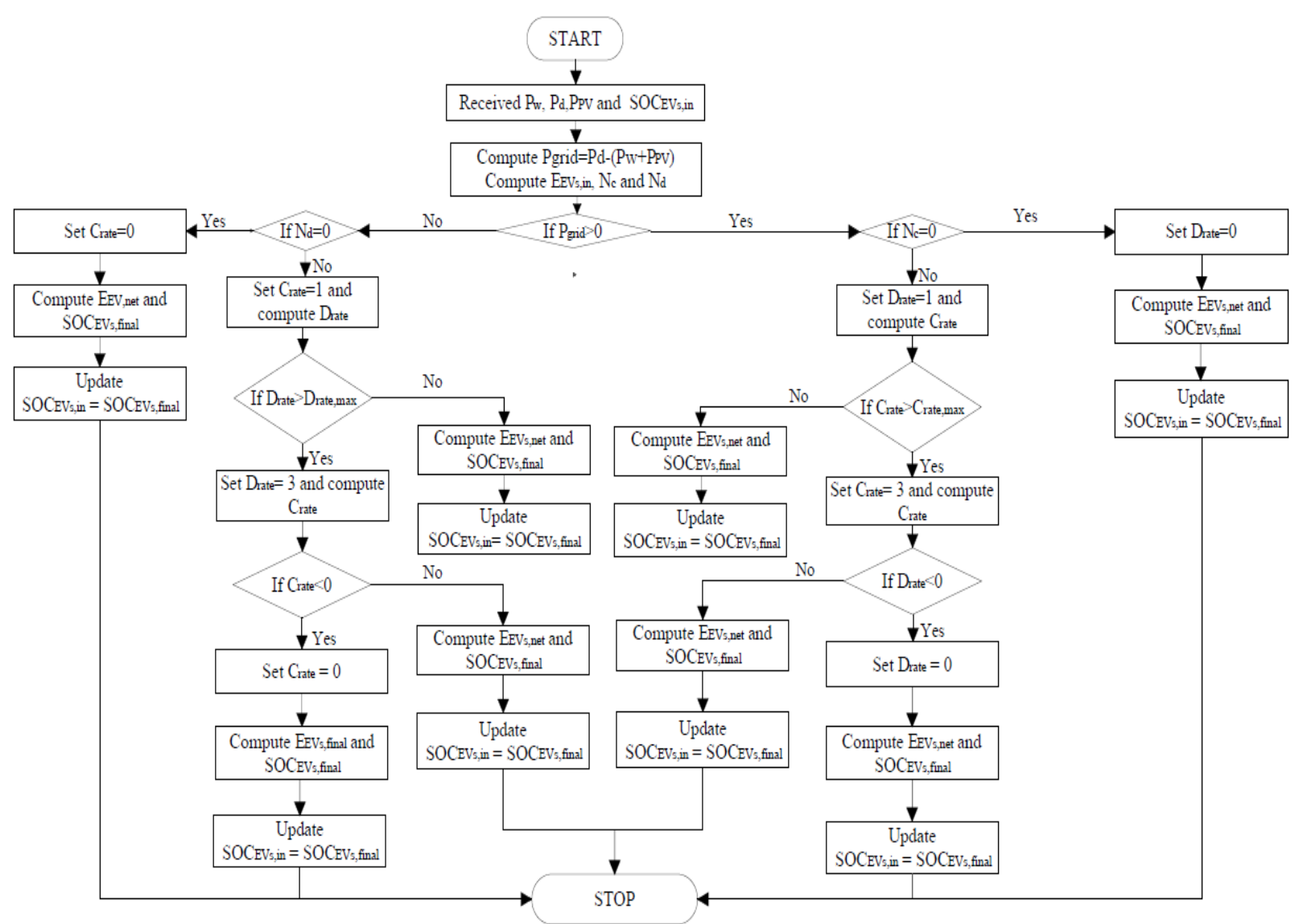

Fig 4. Flow chrat of the proposed system

During the forward simulation procedure, the model

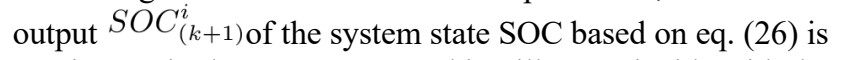
continuous in the state space, and it will not coincide with the nodes of the state grid but is rather between them as shown in Fig. 7.

So in such case, while evaluating the eq.(37) and eq.(38), interpolation is used.

$\operatorname{SOC}_{(k+1)}^{i}=F\left(S O C_{k}^{i}, C_{\text {rate }(k)}^{i}, D_{\text {rate }(k)}^{i}\right.$

In this paper, Dynamic Programming approach searches to find the optimum value of SOC by controlling the $\mathrm{C}_{\text {rate }}$ and $\mathrm{D}_{\text {rate }}$ of the EVs' batteries. Thus, the optimal control scheme is to find the control sequences to minimize the following power function given by eq. (32)

$$
\begin{aligned}
S O C_{k+1}^{i} & =S O C_{k}^{i} \pm f\left(T, C_{\text {rate }(k)}^{i}, D_{\text {rate }(k)}^{i}\right) \\
& =F\left(S O C_{k}^{i}, C_{\text {rate }(k)}^{i} D_{\text {rate }(k)}^{i}\right)
\end{aligned}
$$

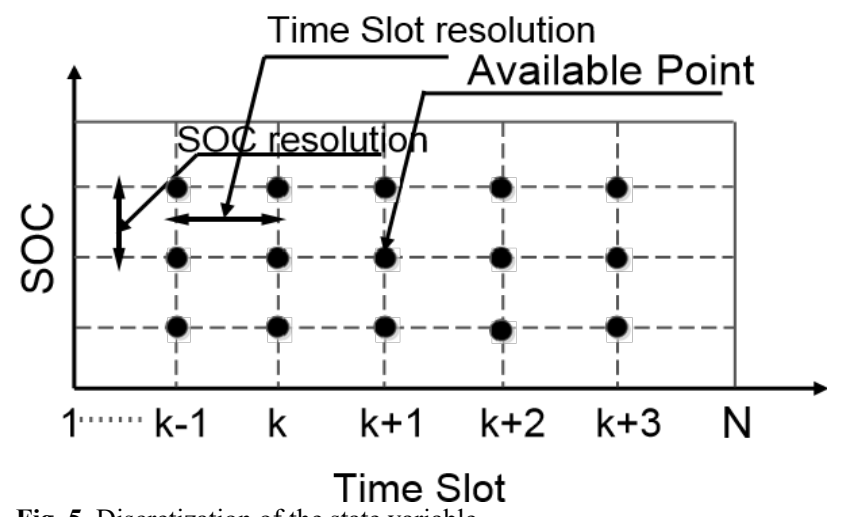

Fig. 5. Discretization of the state variable

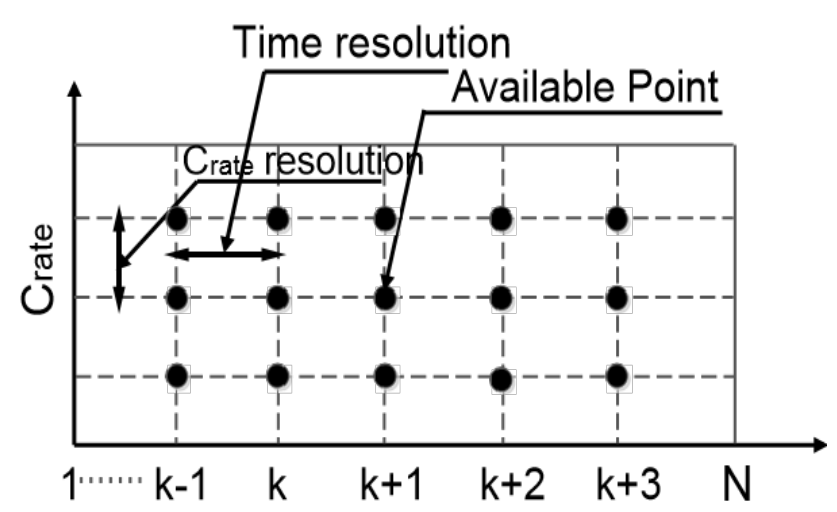

Time Slot

Fig. 6. Discretization of the control variable

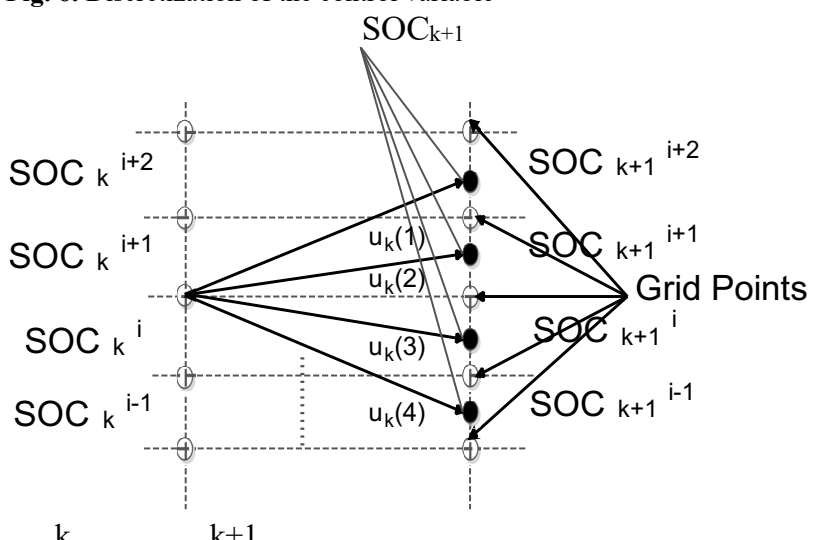

Fig. 7. The interpolation diagram during the backward simulation 

the

Here, $S O C_{k+1}^{i}$ represents the SOC at $(\mathrm{k}+1)^{\mathrm{th}}$ time slot for $i^{\text {th }}$ step.

Similarly, $S O C_{k}^{i}$, represents the SOC at $\mathrm{k}^{\text {th }}$ time slot for the $i^{\text {th }}$ step.

$S O C_{k+1}^{i}=\sum_{n=1}^{30} S O C_{k+1}^{E V, n}$

$\operatorname{SOC}_{k}^{i}=\sum_{n=1}^{30} S_{O} O C_{k}^{E V, n}$

where, $S O C_{k+1}^{E V, n}$ and $S O C_{k}^{E V, n}$ represents the SOC for single $\mathrm{EV}$ at $(k+1)^{t h}$ and $k^{\text {th }}$ time slot for $i^{\text {th }}$ step. Similar expression of SOC can be written at any other time slots.

For the charging case:

$f\left(T, C_{\text {rate }}, D_{\text {rate }}\right)=100(T) C_{\text {rate }}$

and for the discharging case:

$f\left(T, C_{\text {rate }}, D_{\text {rate }}\right)=100(T) D_{\text {rate }}$

Objective function:

$P=\sum_{k=1}^{96} P_{\text {grid }}\left(\operatorname{SOC}_{k}^{i}, C_{\text {rate }(k)}^{i}, D_{\text {rate }(k)}^{i}\right)$

where, $\mathrm{N}$ is the discrete time slots equal to 96 and $P_{\text {grid }}$ is the instantaneous power borrowed from the grid in the $k^{\text {th }}$ slot for $i^{\text {th }}$ step, and is given by:

$P_{\text {grid }}=P_{d}-\left(P_{w}+P_{P V}\right)-P_{E V}^{n e t}\left(C_{\text {rate }(k)}^{i}, D_{\text {rate }(k)}^{i}\right)$

Subjected to equality and inequality constraint:

$P_{E V}\left(C_{\text {rate }}, D_{\text {rate }}\right)=P_{\text {rated }}\left[N_{d} D_{\text {rate }}-N_{c} C_{\text {rate }}\right]$

$C_{\text {rate }}^{\min } \leq C_{\text {rate }} \leq C_{\text {rate }}^{\max }$

$D_{\text {rate }}^{\min } \leq D_{\text {rate }} \leq D_{\text {rate }}^{\max }$

While formulating the forward simulation procedure in the dynamic programming, problem can be described by the recursive eq.(37) and eq.(38). The sub-problem for the $1^{\text {st }}$ slot is:

$P_{1}\left(\operatorname{SOC}_{1}^{i}\right)=P_{\text {grid }}\left(S O C_{1}^{i}, C_{\text {rate (1) }}^{i}, D_{\text {rate (1) }}^{i}\right)$

For the $K^{\text {th }}$ time slot and $i^{\text {th }}$ step,the sub-problem is:

$\mathrm{P}_{\mathrm{k}}\left(\mathrm{SOC}_{\mathrm{k}}^{\mathrm{i}}\right)=\min \left[\mathrm{P}_{\text {grid }}\left(\mathrm{SOC}_{\mathrm{k}}^{\mathrm{i}}, \mathrm{C}_{\text {rate }(\mathrm{k})}^{\mathrm{i}}, \mathrm{D}_{\text {rate }(\mathrm{k})}^{\mathrm{i}}\right)+\right.$ $\left.\mathrm{P}_{(\mathrm{k}-1)}\left(\mathrm{SOC}_{(\mathrm{k}-1)}^{\mathrm{i}}\right)\right]$

where, $\mathrm{P}_{\mathrm{k}}\left(\mathrm{SOC}_{\mathrm{k}}^{\mathrm{i}}\right)$ is the optimal Power function at state $\mathrm{SOC}_{\mathrm{k}}^{\mathrm{i}}$ from the $\mathrm{k}^{\text {th }}$ simulation step to the terminal of the power cycle. Moreover, $\mathrm{SOC}_{\mathrm{k}}^{\mathrm{i}}$ is the state in the $\mathrm{k}^{\text {th }}$ stage when the control variable $\mathrm{C}_{\text {rate }(\mathrm{k}-1)}^{\mathrm{i}}, \mathrm{D}_{\text {rate }(\mathrm{k}-1)}^{\mathrm{i}}$ is applied to state $\mathrm{SOC}_{(\mathrm{k}-1)}^{\mathrm{i}}$ at the $(\mathrm{k}-1)^{\text {th }}$ stage according to the eq. (26).

\section{Results and simulations}

This Section elaborates the results obtained after performing simulations on the proposed system. For simulation purpose, a high rise residential building consisting of 10 apartments has been considered. However, this proposed scheme can be extended to $\mathrm{n}$ number of apartments in the high rise building.
Furthermore, the time duration of 24 hours has been divided into 96 slots of $15 \mathrm{~min}$ each. Therefore, the number of stages are 96 and the number of steps are taken to be 5. Besides, 30 EVs' of Chevrolet are assumed to be present in the parking area of high rise residential building all the time, whose batteries will support the demand. The rated battery capacity of these EVs is $16 \mathrm{kWh}$ and minimum and maximum SOC limits are $10 \%$ and $100 \%$ respectively.

The simulation parameters used in the proposed work has been elaborated in the Table 1.

\subsection{Case Study}

For simulations, the total demand of some high rise building of California city, has been taken after observing its load profile for 24 hours as shown in Fig. 8. In order to meet the demand, PV panels and wind system of suitable capacity has been installed on the roof top of the high rise residential building. The power generated by these sources have been shown clearly in Fig. 9. The total power of these DERs' may not be able to meet the demand of the building.

TABLE I: Parameters used for simulation purpose

\begin{tabular}{|l|r|}
\hline Parameters & Values \\
\hline$P_{P V}^{\text {rated }}$ (Rated power available from PV panel at any instant) & $200 \mathrm{~kW}$ \\
$S O C_{E V}^{\max }$ (Max. SOC of EV battery at any instant) & 100 \\
$S O C_{E V}^{\min }$ (Min. SOC of EV battery at any instant) & 10 \\
$C_{\text {rate }}^{\min }$ and $D_{\text {rate }}^{\min }$ (Min. $C_{\text {rate }}^{\min }$ and $D_{\text {rate }}^{\min }$ of EV battery) & 0 \\
$C_{\text {rate }}^{\max }$ and $D_{\text {rate }}^{\max }$ (Max. $C_{\text {rate }}^{\max }$ and $D_{\text {rate }}^{\max }$ of bV battery) & 3 \\
$E_{\text {rated }}^{\text {EV (Max. energy stored in EV battery at any instant) }}$ & $16 \mathrm{kWh}$ \\
No. of apartments in the residential building & 10 \\
No. of EV in the residential building & 30 \\
No. of Stages & 96 \\
No. of steps & 5 \\
\hline
\end{tabular}

This mismatch of power results in borrowing or delivering power to the SG, which has been depicted in Fig. 10. For instant at 0100 hrs, the power generation of DERs' is less compared to demand, therefore power borrowed from the SG is $59.43 \mathrm{~kW}$. Similarly, at $1200 \mathrm{hrs}$, the power generated is more than the demand therefore, the power diverted to the SG is $32.25 \mathrm{~kW}$. For meeting this gap in the demand and generation, the scheme facilitates the use of EVs' batteries which are categorized into charging and discharging, depicted in Fig. 12. The charging and discharging status of the EVs batteries depends upon the SOC level. If the SOC level of the battery is more than $50 \%$ it is discharging, otherwise charging. Therefore, to manage the demand of the high rise building, energy stored in the EVs' batteries is utilized. Moreover, alteration in the $C_{\text {rate }}$ and $D_{\text {rate }}$ has been carried out for optimized DRM as depicted in Fig. 13 and 14. The alteration in $\mathrm{C}_{\text {rate }}$ and $\mathrm{D}_{\text {rate }}$ has been done as per the algorithm 1, based on Dynamic Programming. Accordingly, the cumulative power extracted from these EVs' batteries has been shown with the help of Fig. 11. At instant 0100 hour, the power generated from DERs' is deficit compared to demand by $59.44 \mathrm{~kW}$. This amount of power has to be completely or partially compensated from the energy stored in EVs' batteries. Therefore, from Fig. 11 it can be inferred that this amount of power is completely met from the discharging EVs' batteries with $\mathrm{D}_{\text {rate }}$ of 1.4. Moreover, the numbers of EVs' that are in charging and discharging mode at this instant are 13 and 17 respectively as shown in Fig. 12. Similarly, at instant 1000 hour it was seen that the $34.47 \mathrm{~kW}$ of additional power is generated by the DERs. Henceforth, this excess power has been completely compensated by charging the EVs' batteries with $\mathrm{C}_{\text {rate }}$ of 0.108 . In this case, the number of EVs' in charging and discharging mode are 29 and 1 respectively. From Fig. 15 
it can be inferred that, the power borrowed from the SG has reduced at most of the instances. For instant at 0100 hour, this power is brought down to $0 \mathrm{~kW}$ from it's previous value of $59.43 \mathrm{~kW}$. Similarly, at 1000 hour the power diverted to the SG has been reduced to $0 \mathrm{~kW}$ from its previous value of 34.47 $\mathrm{kW}$. This power has been utilized for charging the EVs' batteries. Therefore, conclusion can be drawn that the dependency on the SG has been reduced by the inclusion of EVs' as energy storing elements in the high rise building.

For simple understanding, the energy variation of a single EV has been elaborated. Fig. 16 and Fig. 17 shows the energy change and the amount of energy available in battery of the EV for 96 time slots. At instant 0100 hour, the initial energy available in the EVs' batteries is $8.779 \mathrm{~kW}$. Since, the SOC level of the battery is above $50 \%$ so this $\mathrm{EV}$ will be in discharging mode. Hence, the energy available in the EV battery reduces to $4.68 \mathrm{kWh}$ at 0115 hour. Therefore, the change in energy of the EV battery is $4.12 \mathrm{kWh}$. Whereas at 0945 hour, the energy available in the battery of EV is 7.88 $\mathrm{kW}$ and the energy available at the next instant is $8.1 \mathrm{kWh}$. Therefore, the same EV is in the charging mode of operation and the change in the energy of the battery is $0.13 \mathrm{kWh}$. Along with this, the cumulative SOC variation of the EVs' batteries has also been shown in Fig. 18. Therefore, from the ongoing discussion, it can be concluded that the same EV has been utilized as charging and discharging EV for DRM.

\subsection{Comparison and discussions}

Comparison and discussions are necessary to show the effectiveness of any scheme. Since, the objective is to manage the demand response of the high rise residential building by controlling the $\mathrm{C}_{\text {rate }}$ and $\mathrm{D}_{\text {rate }}$ of the EVs' batteries. Hence, to show the effectiveness of the above scheme, the obtained results are compared with scheme where the $C_{\text {rate }}$ and $D_{\text {rate }}$ of the EVs' batteries remained unaltered. Furthermore, to support this, Fig. 19 depicting the comparison has been shown.

Fig. 19(a) shows that the power borrowed from the SG is more when the $\mathrm{C}_{\text {rate }}$ and $\mathrm{D}_{\text {rate }}$ of the EVs' batteries are constant. Whereas, the power borrowed from the SG has reduced by using the proposed scheme. Similarly from Fig. 19(b), it can be concluded that the role played by EVs' batteries for DRM is less significant as compared to proposed scheme. Hence, the utilization of EVs' for DRM is more in the proposed work as compared to the existing schemes. Moreover, from Fig. 19(c) it can be seen, the variation in the SOC level of the batteries are abrupt and fluctuating in comparison to this work where the changes are gradual. Hence, from the ongoing discussion it can be concluded that the EVs' batteries life cycle will be severely affected when the power is borrowed at constant $\mathrm{C}_{\text {rate }}$ and $\mathrm{D}_{\text {rate. }}$

\section{Conclusion}

In this paper, the authors proposed a system framework for DRM of the high rise building which consumes a major portion of the power. In order to fulfill the demand, PV and wind system of suitable capacity have been installed on the roof top of the building. Apart from this, the energy stored in the EVs' batteries has also been explored for DRM. First the demand is met by the power generated by these DERs'. If the demand is left unfulfilled, then the energy stored in the EVs' batteries is utilized

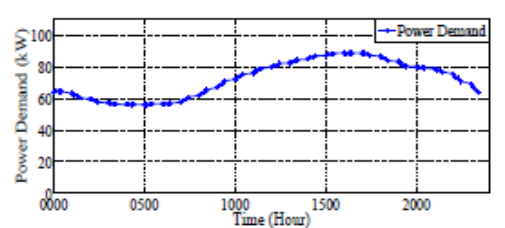

Fig. 8: Demand of high rise residential building

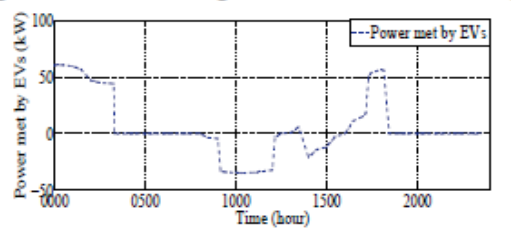

Fig. 11: Cumulative power delivered by EVs' batteries parked at CS

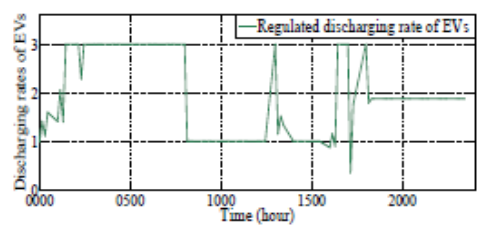

Fig. 14: Instantaneous $D_{\text {rate }}$ variations of the EVs' batteries

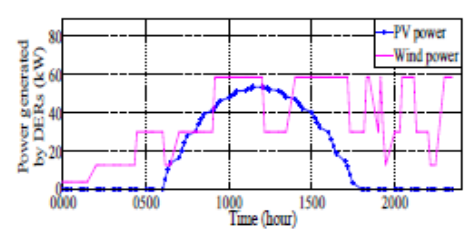

Fig. 9: Power generated by DERs

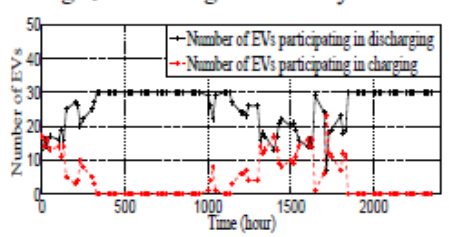

Fig. 12: Total number of charging and discharging EVs'

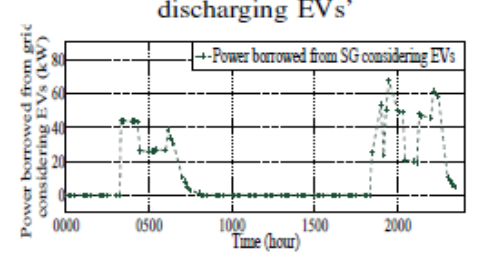

Fig. 15: Power borrowed from SG considering EVs'

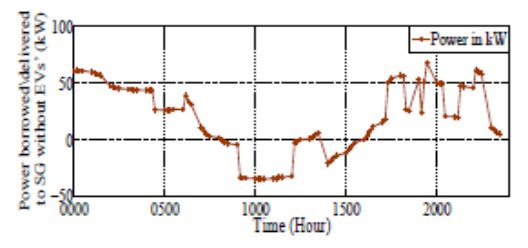

Fig. 10: Demand and generation gap curve

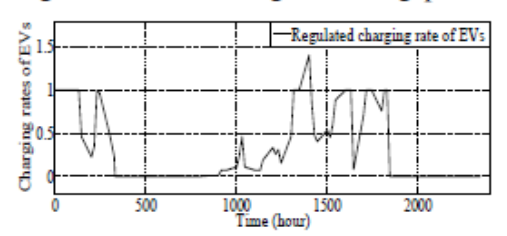

Fig. 13: Instantaneous $C_{\text {rate }}$ variation of the EVs' batteries

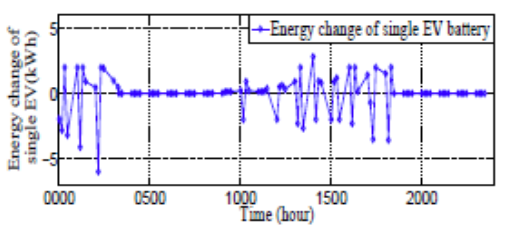

Fig. 16: Rate of change of energy of the EV battery

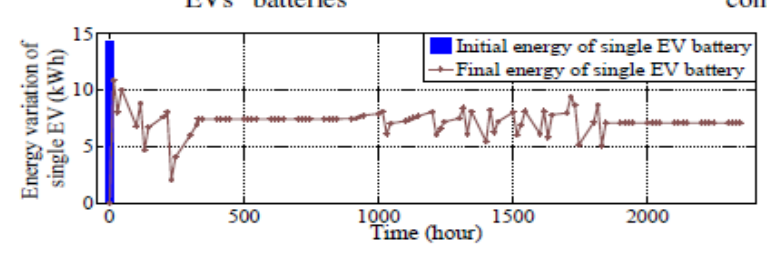

Fig. 17: Energy stored in the EV battery

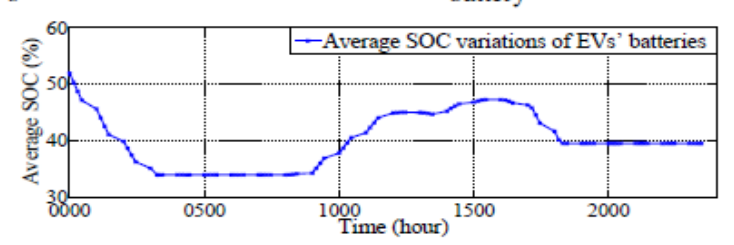

Fig. 18: EVs' average SOC across 24 hours 


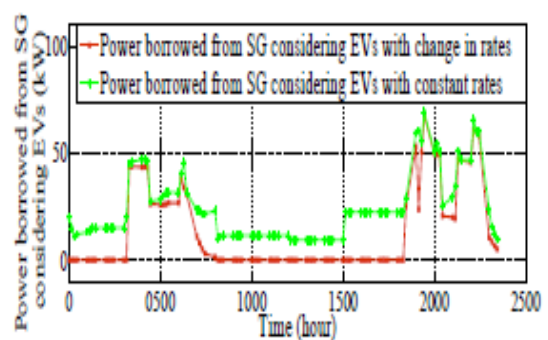

(a) Power supplied by the SG considering EVs' batteries across 24 hours

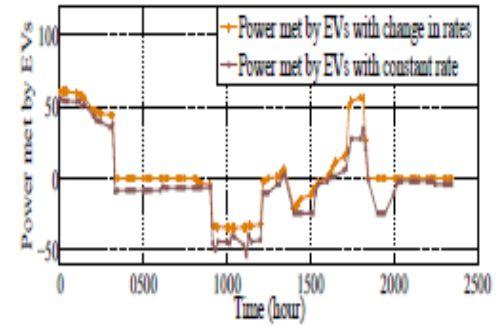

(b) Cumulative power delivered by EVs' batteries across 24 hours

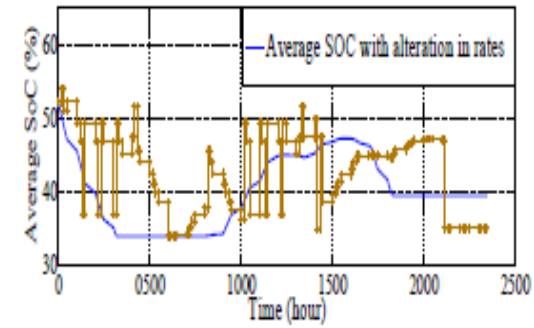

(c) Variation of average SOC of the EVs' batteries across 24 hours

Fig. 19: Comparison with and without charging and discharging rates alterations

Moreover, the alteration in the charging and discharging rates of the EVs' batteries is performed using Dynamic Programming so that no demand of the building is left unmet. Furthermore, setting up of Apartment Energy Control Unit and Charging Station have been proposed, which manage the energy requirements of the system. Henceforth, simulation and results showed the effectiveness of the proposed scheme.
This is an Open Access article distributed under the terms of the Creative Commons Attribution License.

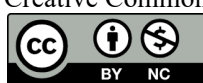

\section{References}

1. K. Moslehi and R. Kumar, "A reliability perspective of the smart grid." IEEE Transactions on Smart Grid, vol. 1, no. 1, pp. 5764, 2010.

2. A. Molderink, V. Bakker, M. G. Bosman, J. L. Hurink, and G. J. Smit, "Management and control of domestic smart grid technology," IEEE transactions on Smart grid, vol. 1, no. 2, pp. 109-119, 2010.

3. S. Salinas, M. Li, P. Li, and Y. Fu, "Dynamic energy management for the smart grid with distributed energy resources," IEEE Transactions on Smart Grid, vol. 4, no. 4, pp. 2139-2151, 2013.

4. W. Tushar, B. Chai, C. Yuen, D. B. Smith, K. L. Wood, Z. Yang, and H. V. Poor, "Three-party energy management with distributed energy resources in smart grid," IEEE Transactions on Industrial Electronics, vol. 62, no. 4, pp. 2487-2498, 2015.

5. S. Shao, M. Pipattanasomporn, and S. Rahman, "Development of physical-based demand response-enabled residential load models," IEEE Transactions on Power Systems, vol. 28, no. 2, pp. 607-614, 2013.

6. S. Maharjan, Q. Zhu, Y. Zhang, S. Gjessing, and T. Basar, "Dependable demand response management in the smart grid: A stackelberg game approach," IEEE Transactions on Smart Grid, vol. 4, no. 1, pp. 120-132, 2013.

7. T.-H. Chang, M. Alizadeh, and A. Scaglione, "Real-time power balancing via decentralized coordinated home energy scheduling," IEEE Transactions on Smart Grid, vol. 4, no. 3, pp. 1490-1504, 2013.

8. D.-c. Gao and Y. Sun, "A ga-based coordinated demand response control for building group level peak demand limiting with benefits to grid power balance," Energy and Buildings, vol. 110, pp. 31-40, 2016.

9. B. Sivaneasan, K. Nandha Kumar, K. Tan, and P. So, "Preemptive demand response management for buildings," IEEE Transactions on Sustainable Energy, vol. 6, no. 2, pp. 346-356, 2015.

10. J. H. Yoon, R. Bladick, and A. Novoselac, "Demand response for residential buildings based on dynamic price of electricity," Energy and Buildings, vol. 80, pp. 531-541, 2014.

11. S. Rotger-Griful, R. H. Jacobsen, D. Nguyen, and G. Sørensen, "Demand response potential of ventilation systems in residential buildings," Energy and Buildings, vol. 121, pp. 1$10,2016$.
12. F. Lauro, F. Moretti, A. Capozzoli, and S. Panzieri, "Model predictive control for building active demand response systems," Energy Procedia, vol. 83, pp. 494-503, 2015.

13. Z. Wu, H. Tazvinga, and X. Xia, "Demand side management of photovoltaic-battery hybrid system," Applied Energy, vol. 148, pp. 294-304, 2015.

14. P. Mesaric and S. Krajcar, "Home demand side management integrated' with electric vehicles and renewable energy sources," Energy and Buildings, vol. 108, pp. 1-9, 2015.

15. H. Kumar Nunna and S. Doolla, "Energy management in microgrids using demand response and distributed storage-a multiagent approach," IEEE Transactions on Power Delivery, vol. 28, no. 2, pp. 939-947, 2013.

16. S. Mocci, N. Natale, F. Pilo, and S. Ruggeri, "Demand side integration in lv smart grids with multi-agent control system," Electric Power Systems Research, vol. 125, pp. 23-33, 2015.

17. A. Ghasemi, S. S. Mortazavi, and E. Mashhour, "Hourly demand response and battery energy storage for imbalance reduction of smart distribution company embedded with electric vehicles and wind farms," Renewable Energy, vol. 85, pp. 124-136, 2016.

18. G. Brusco, A. Burgio, D. Menniti, A. Pinnarelli, and N. Sorrentino, "Energy management system for an energy district with demand response availability," IEEE Transactions on Smart Grid, vol. 5, no. 5, pp. 2385-2393, 2014.

19. T. Wang, D. O'Neill, and H. Kamath, "Dynamic control and optimization of distributed energy resources in a microgrid," Smart Grid, IEEE Transactions on, vol. 6, no. 6, pp. 2884-2894, 2015.

20. K. Clement-Nyns, E. Haesen, and J. Driesen, "The impact of charging plug-in hybrid electric vehicles on a residential distribution grid," IEEE Transactions on Power Systems, vol. 25, no. 1, pp. 371-380, 2010.

21. Y. Ozturk, D. Senthilkumar, S. Kumar, and G. Lee, "An intelligent home energy management system to improve demand response," IEEE Transactions on Smart Grid, vol. 4, no. 2, pp. 694-701, 2013.

22. H. Tischer and G. Verbic, "Towards a smart home energy management system-a dynamic programming approach," in Innovative Smart Grid Technologies Asia (ISGT), 2011 IEEE PES. IEEE, 2011, pp. 1-7. 